\title{
Televisión, juventud y futuro: estudio intercultural con jóvenes costarricenses y alemanes 1
}

\author{
Rolando Pérez Sánchez
}

\begin{abstract}
Resumen
Este artículo examina la relación entre la recepción de series de televisión y la construcción social del futuro personal y social en jóvenes alemanes y costarricenses. Para ello se llevaron a cabo entrevistas semi-estructuradas a jóvenes entre 15 y 17 años de ambos países $(N=40)$. El análisis cualitativo del contenido medial y de las entrevistas se concentró en la distinción de modelos de interpretación cultural (Lüders, 1991), particulares a cada país, que están presentes de forma común tanto en el mundo social representado en la respectiva serie como en el discurso de los y las jóvenes sobre el futuro. A este respecto, se pudo distinguir formas de organización del curso de la vida específicas de cada cultura. Los análisis muestran que: a) la representación del futuro en Costa Rica se estructura en el marco de la experiencia conflictiva de la modernización cultural y de los cambios en el curso de la vida y el período juvenil que ésta lleva consigo, mientras que b) en el caso de Alemania, las representaciones acerca del futuro se organizan en el contexto de un acelerado proceso de individualización institucional de los cursos de vida, que trae aparejado, paradójicamente, nuevas formas de estandarización.
\end{abstract}

\begin{abstract}
The present article examines the relationship between the reception of TV series and the social construction of the future, both personal and social, among Costa Rican and German youths. For this purpose, 40 Costa Rican and German youths between 15 and 17 years old were interviewed using semistructured interviews. Qualitative analyses of media messages and interviews focused on those country-specific models of cultural interpretation (kulturelle Deutungsmuster, Lüders, 1991) that were present in the social world represented in each TV serial as well as in youths' discourse about the future. With this respect, it was possible to distinguish country-specific forms of organization of youth's life course. Data show that a) future representations in Costa Rica are structured within the framework of the conflictive experience linked with the cultural modernization and the concomitant changes in the life course and the youth phase, while b) future representations in Germany are organized in the context of an accelerated process of institutional individualization of life courses, which, paradoxically, is linked with new forms of standardization.
\end{abstract}

\footnotetext{
1 Este artículo constituye un resumen de la tesis doctoral del autor, realizada en la Universidad de Franckfort, Alemania, bajo la tutoría del Prof. Dr. Klaus Neumann-Braun. Por este medio el autor agradece al Servicio de Intercambio Académico Alemán (DAAD) y a la Universidad de Costa Rica por toda la ayuda brindada.
} 


\section{Introducción}

El presente artículo se ocupa de las relaciones entre la recepción de series de televisión y la formación de representaciones acerca del futuro personal y social en dos culturas diferentes, a saber, Alemania y Costa Rica.

En las sociedades contemporáneas la televisión ocupa un papel activo en la comprensión y construcción de la identidad y las representaciones acerca del mundo social (Barker, 1999; Livingstone, 1998; Charlton y Neumann-Braun, 1992). En el contexto actual caracterizado por una acelerada globalización cultural su importancia queda aún más clara, ya que la televisión aporta no sólo a la comprensión de las culturas locales sino también está implicada en la escenificación y difusión de otras formas culturales globales diversas, participando en la llamada hibridación cultural y en el proceso de asimilación y enfrentamiento de lo global por parte de las culturas locales (Pieterse, 1995; Robertson, 1995). En el caso de las series de televisión -género televisivo sobre el que gira la presente investigación- estas tendencias se expresan de manera clara. Las series son difundidas y producidas en todo el mundo y tienen las cuotas más altas de recepción (Barker, 1999). Ellas ofrecen al espectador un espectro amplio de formas de vida social e identidades con los cuales el receptor interactúa.

Ahora bien, los cambios que se llevan a cabo en las culturas locales llevan a transformaciones profundas en el proceso de socialización (Kohli, 1985; Ferchhoff, 1999). En particular, tienen consecuencias directas en la construcción de las identidades sociales y personales, en el curso de vida y las imágenes que los individuos se forman acerca del futuro. Por esta razón esta investigación se dirige al estudio de la apropiación de series por parte de jóvenes costarricenses y alemanes, más si se toma en cuenta que, precisamente, una de las tareas de desarrollo (Grob, A., Flammer, A. y Rhyn, H. 1995) fundamentales en esta fase esta ligada con la formación de las identidades personales y sociales (Widdicombe, 1988; Heitmeyer y Hurrelmann, 1993).

El presente artículo se concentra en la descripción de las modelos culturales de interpretación de la realidad ligados a la construcción de representaciones acerca del futuro, que son comunes tanto en la escenificación del mundo social que hacen series de televisión como en el discurso de jóvenes en Costa Rica y Alemania. De aquí se desprenden dos ejes problemáticos fundamentales: por un lado, están las características del mundo social representado en la serie y su apropiación por parte de los jóvenes ${ }^{2}$. El ocuparse de este aspecto resulta relevante en la presente investigación ya que las representaciones del mundo social que la serie ofrece son asimiladas por los receptores tanto como estructuras de realidad en el presente como formas alternativas de organización social o bosquejos de vida alternativos. Por otro lado, se indaga en las representaciones acerca del futuro social y personal, bajo el supuesto de que ellas se forman en el marco de las concepciones que se poseen acerca del mundo social y del trabajo cotidiano sobre la identidad.

El presente estudio se torna relevante en Costa Rica si se considera que: a) la investigación científico-social sobre recepción televisiva ha tenido hasta el momento un escaso desarrollo en el país, salvo importantes excepciones como la de Lobo y Robert (1997), estudio sobre la recepción de programas infantiles por parte de niños de edad preescolar. Por lo demás, no se reportan hasta la fecha estudios realizados con jóvenes. b) De igual manera la investigación científico-social sobre representaciones de futuro se ha concentrado sobre todo en la determinación de metas sin detenerse en el análisis de la génesis psico-social, particularmente en el lugar que ocupa en la construcción social del curso de la vida (Bermudez, 1994; Dobles y Fournier, 1996).

A continuación se presenta la perspectiva teórica que guía la presente investigación. Posteriormente se describe la estrategia metodológica empleada. Seguidamente se presentan resultados relevantes, haciendo énfasis sobre todo en semejanzas y diferencias entre el mundo social escenificado en la serie y las representaciones del futuro social y personal construidas por los jóvenes de cada país. En el último apartado, se establecen algunas comparaciones fundamentales entre ambos países.

\footnotetext{
${ }^{2}$ Cuando en el artículo se hace referencia a "los jóvenes" o "los entrevistados", se está considerando tanto a las como a los jóvenes así como a los entrevistados y las entrevistadas. Esta medida se toma con la intención de facilitar la lectura del texto.
} 


\section{Televisión, socialización y recepción}

La televisión, entendida como un agente cultural de sentido, participa junto con otras instancias en el proceso de socialización. Ahora bien, mucho se ha discutido sobre los alcances de su impacto en las estructuras socio-cognoscitivas o emocionales. De los resultados hasta ahora obtenidos no se puede inferir, sin embargo, que exista un efecto perturbador o limitador de dichas estructuras que pueda serle achacado exclusivamente a la televisión (Hodge y Tripp, 1986; Buckingham, 1993). Más allá de la búsqueda de patrones del tipo causa - efecto, el lugar que ocupa la televisión como agente socializador debe ubicarse en el contexto de su papel en la estructuración del mundo social moderno. Charlton y Neumann (1990) en el marco de una teoría de la acción de los procesos de recepción y comunicación medial, señalan que la relación entre el receptor y los medios de comunicación masiva tiene un carácter doble: por un lado, forma parte del proceso de individuación, caracterizado por la apropiación reflexiva de los mensajes, es decir, por el procesamiento activo de dichos ofrecimientos de conformidad con los intereses, temas y tareas en los cuales están inmersos los individuos en un momento dado. Por otro lado, los mass media se constituyen de forma simultánea en factores que favorecen la universalización y la estandarización. Se trata de nuevas formas de control social mediadas por particulares pautas de consumo, la predilección de ciertos estilos de vida o la divulgación de discursos estereotipados.

En este sentido, pueden distinguirse específicamente tres funciones de la televisión en el proceso de socialización:

a) La televisión contribuye -junto con otros medios- a la construcción cotidiana de la identidad (Charlton y Neumann, 1990, 1992; Frotz, 1996; Mikos, 1994b): se parte del supuesto de que el espectador se vincula activamente con los ofrecimientos televisivos. Es en este contexto que el receptor se apropia o rechaza formas de pensamiento y acción o de evaluación de la realidad social y del sí-mismo. Los personajes -en tanto que bosquejos biográficos-, las narraciones -en tanto experiencias y situaciones posibles- y la escenificación de la vida cotidiana -en tanto que formas posibles de interacción social y de enfrentamiento de problemas y conflictos- representan contenidos fundamentales de la televisión, con los cuales los individuos se confrontan y comparan con su propia experiencia. De la diversidad de mensajes existentes el sujeto selecciona y se apropia de aquellos mensajes que le resultan significativos en un momento o espacio social dado y de conformidad con las tareas de desarrollo que él o ella deben enfrentar, integrándolos a sus "bosquejos de identidad" existentes. La televisión se integra además en el trabajo reflexivo sobre la identidad en forma de discursos sobre sí-mismo (Barker, 1997; Giddens, 1991; Gergen, 1994), proveyendo diferentes narrativas que son evaluadas por los individuos. Tales discursos incluyen otros contextos culturales, los bosquejos de vida de otras personas y grupos sociales diferentes a los del espectador, pero también presentan formas de vida similares o deseadas por éste, contribuyendo de esta manera a la delimitación de la identidad social y personal por medio del ofrecimiento de categorías acerca del endogrupo, el exogrupo y de sí-mismo (Turner, 1987; Barker, 1997).

b) La televisión contribuye (al igual que otros medios de comunicación masiva) a la estructuración de la vida cotidiana, determinándola y siendo determinada por ella (Livingstone, 1998; Mikos, 1994b; Silverstone, 1994). Integrándose dentro de las rutinas cotidianas como complemento a otras actividades u ocupando espacios definidos, creándose por ésta vía rituales de uso definidos. Igualmente la televisión juega un papel importante en las conversaciones cotidianas mediante su incorporación en forma de temas que favorecen la interacción, en particulares usos del lenguaje o en formas de tematización de la realidad social así como de la propia biografía, es decir, el conjunto de experiencias vividas así como las expectativas, deseos o temores sobre el futuro. El material televisivo puede ocupar un lugar central o marginal en la conversación, lo relevante aquí es que está presente junto con otras informaciones, saberes o experiencias biográficas como un elemento para la interpretación del mundo (Peiser, 1996).

c) Finalmente, la televisión contribuye a la formación de competencias televisivas: en el transcurso de la "socialización televisiva" los sujetos se apropian de las estructuras de narración y representación que caracterizan a cada género televisivo, así como el manejo de los rasgos generales de los roles y scripts que los actores en cada género se espera que desempeñen (Pasquier, 1997). Esto implica la formación de esquemas cognoscitivos a partir de los cuales se interpretan las particularidades formales, semióticas y estéticas de cada género. Al mismo tiempo estas competencias se insertan dentro del nivel más amplio de la Socialización medial, de modo que unos medios aportan elementos para la comprensión de los otros y viceversa. 
Ahora bien, las anteriores consideraciones obligan a hacer una definición del proceso de recepción medial. Según Charlton (1997), la recepción se refiere a la relación y procesamiento de los ofrecimientos mediales que efectúa el espectador. Inicia con la atención hacia determinado medio, por lo general después de la elección de un determinado medio o programa. El proceso de recepción implica una particular relación entre receptor y mensaje -como se verá más adelante-. Por lo general se sucede, como ya se ha señalado, en el marco de comunicaciones sociales o rutinas cotidianas. La última fase de la recepción es el proceso de apropiación (Aneignung), en donde se vinculan la experiencia medial y los mundos de vida de los receptores, aspecto cuya realización puede ser inmediata o mediata a la recepción misma del material televisivo. Dicha fase es definida como el proceso de asimilación de los contenidos del medio de conformidad con la biografía, el marco social así como las competencias y experiencias mediales (Charlton y Neumann, 1992; Hepp, 1998).

En el marco del enfoque que orienta el presente artículo, se puede caracterizar la relación entre recipiente y mensaje, como una relación entre lector y texto, que va más allá del enfoque causalista de las investigaciones clásicas sobre el efecto de los medios (Livingstone, 1996; Charlton, 1997; Hall, 1996). Desde esta perspectiva el texto no contiene un significado único. De allí se desprende que codificación y decodificación del material no conducen necesariamente a los mismos significados, por lo que a partir del texto no se puede obtener todas las posibles interpretaciones que en una sociedad dada se puedan extraer del texto mismo. En última instancia, la lectura o interpretación queda supeditada al lector real (Hall, 1996). En las lecturas que hacen los receptores están envueltas sus convicciones, conocimientos y juicios sociales, así como sus intereses y experiencias. De igual manera los lectores son socialmente diversos y heterogéneos, de forma tal que las lecturas se encuentran en dependencia con el marco sociocultural o económico en el que los individuos están inscritos. No obstante, es importante poner de relieve que el texto mismo contiene instrucciones para su interpretación. Ellos transportan consigo ciertas lecturas predominantes que le son impuestas en su producción y que suponen la existencia de un lector ideal. Igualmente contienen informaciones ligadas a aspectos formales, estéticos y narrativos característicos del programa o género en cuestión (Charlton, 1997). Por último, cabe agregar que el receptor se vincula con textos que también son diversos en estructura, contenido y forma, lo que significa que la recepción está supeditada al género televisivo y el tipo de participación o compromiso que el texto evoca. Cada texto ofrece determinadas perspectivas narrativas, por lo que los receptores no se vinculan con el medio de forma general u abstracta, sino con determinados géneros. El género sería una forma de contrato sobre el cual el texto y el lector establecen relaciones de negociación (Livingstone, 1996).

En el presente artículo el análisis se focaliza en un género que no sólo es exclusivo de la narrativa televisiva sino que es parte fundamental de los otros medios (Mikos 1994a; Eco 1988). La estructura serial está presente en la radio, el film, la televisión, la literatura o los periódicos. La estructura serial como medio narrativo se considera un género de difícil clasificación, sobre todo en lo que respecta a los contenidos y modelos de significación que éstos contienen, los cuales difícilmente se pueden ordenar en esquemas morales o ideológicos definidos. En ella están presentes de forma paralela, reproducción e innovación (Eco, 1988), realidad y fantasía (Allen, 1995; Martín-Barbero, 1995), tradición y modernidad (Martin-Barbero, 1995 y López, 1995), pasado, presente y futuro (Allen, 1995).

Las series se pueden clasificar en tres tipos según sus formas narrativas (Mikos, 1994a; Cantor y Pingree, 1983). Es importante aclarar, sin embargo, que la tendencia actual en la producción de series, se orienta a hacer una mezcla de diferentes tipos, incluso es frecuente el recurrir a otros géneros:

1) Mini-series. Se trata de una estructura narrativa cerrada, la cual consta de un principio y un final definidos, orientándose hacia el futuro y su desenlace final. Las historias pueden narrar la vida de una persona o la de un grupo o comunidad.

2) Series. Al interior de este tipo cada capítulo es una unidad. Aquí se presentan conflictos o problemas que son resueltos en el mismo capítulo, sin que haya continuidad narrativa o una evolución de las biografías.

3) Serials, telenovelas o Soap Operas. Este es el tipo en el que se concentra la presente investigación. Se caracteriza por una narrativa abierta, en donde cada capítulo mantiene relaciones de continuidad. Se trata de una narración fragmentada, sin un final definido. Está compuesta por diferentes líneas narrativas o historias que corren paralelas y se relaciones entre sí. Según Allen (1995) y Livingstone (1998), los espacios entre un capítulo y otro tienen un papel fundamental en la 
interpretación, apropiación e incorporación social del contenido de las series, aspecto que recuerda el desarrollo temporal de la vida cotidiana, el cual tiene un carácter también fragmentado. Livingstone (1998) señala dos cualidades de los serials. Por un lado, los significados negociados entre el espectador y la serie no se reducen a un capítulo en particular, sino a su estructura total. Por otro lado, se promueve el papel activo del espectador, permitiéndole interpretar el material ofrecido, lo que asegura a su vez el mantenimiento de los espectadores a largo plazo. Aspecto común a todos los Soaps es que la narración gira en torno a un grupo, sea éste una familia, una comunidad o un grupo de amigos o enemigos. Otra característica básica de estas series es el recurso al melodrama (Allen, 1995; Mikos, 1994a; Frey-Vor, 1990), es decir, la presentación exacerbada de emociones (en el marco de relaciones de parentesco, amistad o de amor/odio), mediante la presentación de personajes unidimensionales, apelando a la dicotomía bondad - maldad.

\section{Identidad y representaciones del futuro}

En el apartado anterior queda claro el papel que juega la televisión no sólo en la construcción social de la realidad, sino también su aporte en la configuración de estructuras sociales de posibilidad, mediante la presentación de estilos, cursos y formas de vida, así como interacciones sociales, que se incorporan como material social para la formación de la identidad y en particular de los bosquejos de vida. En la literatura internacional, las representaciones de futuro han sido estudiadas desde la perspectiva de las llamadas future orientations. Las orientaciones de futuro han sido objeto de estudio de la investigación social desde hace ya varias décadas (Lewin, 1951; de Volder, 1979; Nurmi, 1989). No obstante, no puede identificarse un modelo teórico sistemático sobre el tema, ya que el alcance de buena parte de los estudios es descriptivo. Las investigaciones revisadas hacen énfasis en diferentes dimensiones: algunas abordan fundamentalmente los elementos cognoscitivos, otras los aspectos motivacionales, otras ponen el énfasis en la acción, mientras que las más recientes se concentran en la producción narrativa acerca del futuro. Finalmente cabe recalcar, que a pesar de la variedad de núcleos de investigación, los estudios se han valido de los mismos recursos metódicos: el uso de cuestionarios, estructurados o semiestructurados y el análisis cuantitativo (Greene, 1986; Münchmeier, 1997; Nurmi, Poole, y Seginer, 1995; Trommsdorff, Lamm, y Schmidt, 1979).

Por orientaciones de futuro se entiende aquí aquel componente de la identidad ligado a la comprensión y planificación del futuro personal y social. Este componente es abordado en esta investigación como esquemas socio-cognoscitivos, de modo que la producción discursiva de dichas orientaciones va ser estudiado como representaciones acerca del futuro. Dichas representaciones son construidas socialmente tanto en el marco de las interacciones sociales como en el contexto de las pautas institucionales vinculadas en la estructuración del curso de la vida, cuya configuración está ligada a los recientes procesos de diferenciación social y la progresiva transformación cultural de las formas de vida.

Considérese ahora el lugar que ocupa la dimensión de futuro en la construcción cotidiana de la identidad. Al investigar las orientaciones de futuro como componentes de la identidad se parte del carácter multiperspectivista del sí-mismo. Aquí no se enfatiza en la unicidad o la unidimensionalidad de la identidad, sino en la diversidad y la relación dínámica -e incluso contradictoria- entre sus componentes (Bilden, 1987; Markus y Wurf, 1987; Hermans y Kempel; 1993; Straus y Höfer, 1997). Estos componentes representan tematizaciones heterogéneas del símismo a las cuales los sujetos acuden cotidianamente y que se organizan como perspectivas de la identidad. Según Straus y Höfer (1997) el desarrollo, predominio y la selección de estas perspectivas o tematizaciones, dependen de varios factores como: la fase del curso de la vida en la que se ubica el individuo, del nivel de diferenciación del mundo de vida, de los estilos de vida o el contexto cultural en el que se desenvuelve el sujeto, así como de los ofrecimientos de los medios de comunicación masiva.

Como contraposición a una identidad concebida como compacta y rígida, se parte del supuesto de que la identidad es el resultado de una constelación de identidades parciales. Aquí se considera la metáfora de un Self en constante diálogo con diferentes voces (Herman y Kempen, 1993), las cuales no constituyen solamente las diferentes perspectivas de sí-mismo sino también, los otros, las instituciones y los objetos sociales (en el sentido de T. Habermas, 1996). Se trata de diálogos imaginarios entre diferentes elementos coordinados por el $I$ que en ese momento es predominante. Por supuesto estos diálogos no son siempre simétricos, las relaciones asimétricas 
ligadas a vínculos de poder interiorizados, están incluidas también como parte integral. Estas consideraciones se basan en los supuestos de Vigotsky (1964) y Mead (1967), quienes sostienen que la fundación del sí-mismo solo se da a partir de la apropiación de las interacciones sociales. En ese sentido, la identidad sería el resultado de la constelación de relaciones sociales en un sujeto concreto, estando implicados procesos de diferenciación e interiorización con respecto a dichas interacciones y sus actores.

Una de esas identidades parciales está ligada con la dimensión de futuro. Esta se ha investigado en los últimos años bajo el concepto de possible selves (Cross y Markus, 1991; Markus y Nurius, 1986; Straus y Höfer, 1997; Bilden, 1997). Según Markus y Nurius (1986) los sí-mismos posibles representan aquella dimensión de la identidad que se ocupa del futuro personal y social. Estas están ligadas al procesamiento cognitivo-afectivo sobre las posibilidades de desarrollo futuro. Los también llamados proyectos de identidad se desarrollan a partir de los aspectos deseados y temidos, que están contenidos en las representaciones del futuro, y permiten a los sujetos la organización, significación y orientación de las metas, temores, motivaciones o aspiraciones. Estos possible selves son generados en relación directa con los contextos socio-culturales e históricos, en que se desenvuelven los sujetos, así como con las imágenes ofrecidas por los medios de comunicación, los grupos de referencia y las experiencias inmediatas de los individuos (Markus y Nurius, 1986).

Buena parte de las investigaciones sobre orientaciones de futuro focalizan su interés en los jóvenes, precisamente porque la adolescencia es concebida como período de exploración y preparación para la futuro, y en particular para la vida adulta. ( Nurmi, Poole y Seginer, 1995; Nurmi, Seginer, Poole, 1995; Nurmi, 1989; Poole y Cooney, 1987, Trommsdorff, Lamm y Schmitdt, 1979). En la literatura revisada se le atribuyen a este período de la vida dos tareas básicas: a) los jóvenes tienen que hacerle frente a una serie de tareas normativas y expectativas sociales, provenientes de diferentes grupos e instituciones en los que son participes, como la familia, el grupo de pares o la escuela y que están ligados con la asunción de nuevos roles o el seguimiento de las secuencias institucionales vinculadas a la formación educativa y laboral. Es decir, se concibe como un período en la cual se toman decisiones que tienen consecuencias directas para el desarrollo posterior del curso de la vida, como son la escogencia de un oficio, una carrera, la definición de un estilo de vida, la vida en pareja o la formación de una familia. b) La reflexión sobre el futuro forma parte de la formación de la identidad, la cual es la tarea básica de este período del curso de la vida. El ocuparse sobre los cursos posibles que tomarán sus bosquejos de vida resulta ser un contenido básico en la reorganización, construcción y apropiación reflexiva de la identidad personal (Nurmi, Pooli y Seginer, 1995)

A estos aspectos se le debe agregar otra tarea básica en este período. Se trata de la posición que los jóvenes ocupan en la sociedad, definiendo sus grupos de pertenencia y delimitando los exogrupos, es decir, la configuración y apropiación de la identidad social (Turner, 1987; Widdicombe, 1988). Esto implica para los sujetos indagar en diferentes perspectivas ideológicas y en diversos discursos morales o político-sociales, de modo que puedan definir los contornos del propio grupo (Poole y Cooney, 1987; Heitmeyer y Hurrelmann, 1993). De esta forma, los cambios ocurridos en las perspectivas de tiempo de los jóvenes no deben atribuirse únicamente al desarrollo cognoscitivo o a la formación de la identidad personal, sino a la experiencia social acumulada (Greene, 1990), la cual posibilita la construcción de una narrativa del sí-mismo, un discurso acerca del pasado, el presente y el futuro del individuo.

Ahora bien el lugar del período juvenil en la configuración de las representaciones acerca del futuro debe abordarse además desde la posición que ocupan los jóvenes en tanto grupo social y las características de su conformación histórica en los países occidentales en los últimos 50 años- sobre todo en las sociedades altamente industrializadas - (Fuchs, 1983). En el contexto de una progresiva institucionalización del curso de la vida, el período juvenil ocupa un particular interés ya que es el foco de una serie de transformaciones que van a repercutir sobre todo el curso de la vida. De esta manera, los procesos de creciente "de-estandarización" y "biografización" ocurridos al interior de este período de vida son el resultado de una serie transformaciones históricas que han llevado a la estructuración de la juventud en tanto que grupo social con características particulares, con un espacio de acción relativamente autónomo, lo cual se sucede en el marco del llamado proceso de individualización estructural (Beck, 1986; Heitmeyer y Olk 1995). Dichos cambios se dirigen a un divorcio progresivo con respecto a pautas de acción dirigidas a reproducir un curso de vida definido por la tradición - el cual gira en torno a la familia, roles de género estereotipados y preceptos religiosos -, relacionándose más bien, con una progresiva apropiación reflexiva de la propia biografía y la tendencia hacia la construcción autónoma del curso de la vida, contenidos básicos de 
la modernización socio-cultural. Estas transformaciones tienen un carácter heterogéneo y contradictorio tanto entre las culturas como al interior de cada cultura, dependiendo de la posición que ocupan los individuos o los grupos en la estructura social, manteniendo su validez factores diferenciadores como origen socio-económico, sub-cultura, género, etnia o edad.

Permanece abierta la pregunta de hasta qué punto Costa Rica es participe parcialmente o en su totalidad de estas transformaciones, ya que en este país se tienen pocas referencias al respecto. No obstante, Torres-Rivas (1993) formula algunas observaciones sobre los cambios sociohistóricos ocurridos en las últimas décadas en Costa Rica que apuntan en la misma dirección que lo señalado por Fuchs (1983) o Büchner (1995), con la salvedad que en el caso costarricense los cambios se han llevado a cabo de manera más lenta y desigual, siendo válidos solo para ciertos ámbitos y grupos sociales, resultando que las contradicciones entre tradición y modernización al interior del curso de la vida son uno de los rasgos principales de la vivencia de los jóvenes. De manera hipotética se considera en la presente investigación, que los cambios fundamentales sucedidos en los países occidentales desarrollados también están aconteciendo en la actualidad costarricense. Por supuesto, ésto supone la existencia de diferencias en la estructuración histórica de la juventud en tanto grupo social, diferencias que no van a ser abordadas en detalle en la presente investigación, pero cuyo correlato va a estar presente en el discurso de los jóvenes sobre sí-mismos, su vida cotidiana y la sociedad, como se verá más adelante.

\section{Método}

El criterio de selección de la serie en cada país, fueron los ratings o lista de programas más vistos por los jóvenes, escogiendo las Serials que en el momento de la recolección de datos fueran las preferidas por los jóvenes de ese grupo de edad. En Costa Rica se escogió la serie "El Barrio", mientras que en Alemania la serie "Gute Zeiten - Schlechte Zeiten" ("Buenos tiempos malos tiempos"). De cada serie se grabó en video una secuencia de 10 capítulos. En Costa Rica se grabaron las series correspondientes al período julio-setiembre de 1997 (capítulos 32-41) y en Alemania las correspondientes al mes de febrero de 1998 (capítulos 1455-1464).

Para la recolección del material empírico se recurrió a una entrevista semi-estructurada, la cual está compuesta de dos fases: 1) en un primer momento se miró un capítulo de la serie junto con los jóvenes. Esto tiene como objetivo crear un marco comunicativo común a partir del cual llevar a cabo la entrevista, proveyendo temas de conversación. 2) La entrevista en sí: aquí se siguió el modelo de la llamada entrevista "centrada en problemas" (Problemzentriertes Interview, Witzel, 1985), la cual tiene por objetivo centrarse en temas que son relevantes para el problema de investigación. Aquí se busca crear un contexto conversacional, promoviendo respuestas argumentativas y narrativas. Se recurrió a una guía de entrevista, que sirvió de apoyo para el entrevistador. La formulación de preguntas o temas fue, sin embargo, dependiente del desarrollo de la entrevista, por lo que no siguió un orden fijo. Aspectos centrales de la entrevista fueron solicitar a los jóvenes la reconstrucción de la serie así como la comparación entre su experiencia cotidiana, su representación del mundo social y de sí-mismo y lo que acontece en la serie. Esto permitió el acercamiento al procesamiento cognoscitivo de dicho material, así como a la determinación de las estructuras sociales de sentido a las que el receptor recurre para la interpretación de la serie

Se realizaron 40 entrevistas a jóvenes entre 15 y 17 años, 20 en Costa Rica y 20 en Alemania (10 mujeres y 10 hombres en cada país). Todos los jóvenes proceden de zonas urbanas y pertenecen a los sectores medios. La casi totalidad de los padres y madres de los entrevistados en ambos países, son profesionales, tienen una formación técnica calificada o se dedican al comercio. Las familias de los entrevistados son familias nucleares, compuestas por padre, madre e hijos (máximo cinco en Costa Rica, mientras que en Alemania tres). Los medios de comunicación masiva, en particular la televisión y la música, ocupan una posición relevante dentro de la vida cotidiana de los jóvenes entrevistados en ambos países. En Costa Rica todos los entrevistados al igual que sus padres son costarricenses, pertenecientes a la mayoría -étnica mestiza-. De forma similar, en Alemania todos los entrevistados son alemanes, aunque en dos de los casos sus padres procedían de otros países: Uganda y Yugoslavia.

Las entrevistas se llevaron a cabo en centros de enseñanza secundaria pública de San José y de Frankfurt. Todas fueron grabadas en audio-cassettes. Las entrevistas en Costa Rica fueron realizadas por el autor, mientras que las entrevistas en Alemania fueron realizadas por entrevistadores alemanes previamente entrenados, esto con el objetivo de mantener el marco 
cultural en el que las entrevistas fueron llevadas a cabo. Las entrevistas en Costa Rica fueron realizadas entre agosto y setiembre de 1997, mientras que las alemanas entre abril y setiembre de 1998.

Como ya se ha venido señalando el análisis de este material tiene como objetivo el determinar los modelos culturales de interpretación (kulturelle Deutungsmuster) implicados en la representación del futuro común tanto al mundo social escenificado en la serie como en el discurso de los jóvenes. El análisis de modelos de interpretación (Deutungsmusteranalyse) se basa en una perspectiva metodológica desarrollada en los últimos 30 años al interior de las ciencias sociales alemanas y en el marco de la investigación cualitativa, que tiene como objetivo la determinación de estructuras sociales de sentido que sirven de base para la interpretación y construcción del mundo social (Lüders, 1991; Neumann-Braun, 1993; Oevermann, 1973).

Neumann-Braun (1993) señala que se han utilizado una diversidad de métodos de análisis para su estudio, desde la llamada hermenéutica estructural o el análisis de conversaciones hasta procedimientos fenomenológicos, reductivos o de parafraseo. En la presente investigación se recurre específicamente a un análisis cualitativo de contenido (Mayring, 1997; Glaser y Strauss, 1998). Se trata de lo que Mayring (1997) llama un análisis de contenido estructurante. Con este procedimiento lo que se pretende es el resumen y la categorización del material, lo que permite la definición de dimensiones estructurantes para la comprensión del fenómeno en estudio.

En particular se recurrió al modelo de la grounded theory ("teoría fundamentada"), diseñado inicialmente por Glaser y Strauss (1998) en el ámbito de la sociología cultural interaccionista, el cual se ha constituido en uno de los principales pilares del análisis de contenido cualitativo. Se trata de una estrategia fundamentalmente inductivista de análisis, donde las categorías de análisis, hipótesis de investigación e interpretaciones están supeditadas a los datos, lo cual lo diferencia de los análisis de contenido clásico (Bauer, 2000), donde las categorías son definidas a priori, es decir, a partir de un marco teórico-hipotético predeterminado, que por lo demás impiden la emergencia de lo nuevo, a partir de una lógica de supeditación de los datos a teorías preestablecidas (Oevermann, 1991). La grounded theory se le llama también "método de comparación constante" (Valles, 1997), cuyo objetivo original es la generación de teorías, recurriendo a la saturación de información como herramienta básica para su fundamentación.

Strauss y Corbin (1998) han sistematizado un procedimiento para la realización de esta propuesta de análisis de contenido, la cual sirvió de base para la realización de la presente investigación. Se pueden distinguir las siguientes fases: 1) codificación abierta, 2) codificación axial y 3) codificación selectiva. En la primera fase se hace una delimitación de las dimensiones generales de análisis y se identifican categorías y subcategorías, para lo cual se parafrasean pasajes o seleccionan ejemplos claves. Esto se lleva a cabo con cada entrevista o capítulo de la serie, generando interpretaciones preliminares. En la segunda fase, se procede a una revisión y reformulación de las categorías, estableciendo relaciones entre las subcategorías y las categorías correspondientes. En la tercera fase se procede a la integración del material y la sistematización teórica de los resultados e interpretaciones preliminares, encontrando por esta vía determinados modelos culturales de interpretación.

Para el caso del análisis de las series, la dimensión básica a indagar son las características del mundo social escenificado en cada serie. En lo que respecta al análisis de las entrevistas se pueden distinguir dos dimensiones básicas: las representaciones acerca del futuro y la apropiación de la serie.

Por último, para probar las categorías se recurrió a un criterio de validez interna que es parte intrínseca del método de comparación constante (Glaser y Strauss, 1998 y Steinke, 1999). Por un lado, se consideró el criterio de saturación de información para cada dimensión. Por otro lado, se procedió a la comparación entre las categorías correspondientes a una dimensión y los resultados encontrados en cada entrevista o cada capítulo de la serie con el resto. En los casos que así lo requirieran se procedió a la reformulación de las categorías, manteniéndose aquellas que eran respaldadas ampliamente por los datos.

Una vez realizados los análisis para cada país se procedió a la comparación de ambos resultados, para lo cual se distinguieron semejanzas y diferencias para cada una de las dimensiones estudiadas.

A continuación se presentan los principales resultados de investigación obtenidos. Se trata de un resumen de los mismos y por razones de espacio no se presenta el detalle de los resultados encontrados para cada dimensión. El foco de atención se dirige más bien a las relaciones entre 
dichas dimensiones, es decir, la identificación de modelos culturales ligados a la construcción social del futuro.

\section{E1 mundo social en la serie "E1 Barrio" y las representaciones del futuro en jóvenes costarricenses}

El mundo social escenificado en la serie "El Barrio" se caracteriza por los conflictos, rupturas y tensiones entre sus componentes. Por un lado, se presenta una sociedad, la cual se concibe a sí misma como comunidad, esto es, como un espacio de cohesión, solidaridad y armonía. Por otro lado, se encuentran conflictos, los cuales amenazan a esa comunidad y que están en claro conflicto con ella. Dos tipos de factores ejercen particular presión: a) factores sistémicos, los cuales se reflejan en el ejercicio corrupto del poder político o en la expansión de la racionalidad orientada a fines del subsistema económico, b) tendencias modernizantes, las cuales promueven la diferenciación cultural y se expresan en cambios en la juventud como en una reestructuración de la comprensión que tienen los jóvenes de sí-mismos y de las tareas institucionales y normas de acción, que deben cumplir en este período. Lo que aquí se escenifica es la particular experiencia de la transición de un mundo tradicional a una sociedad moderna. En la serie el mundo tradicional está vinculado con una "comunidad imaginaria" (Anderson, 1998), la cual le otorga sentido y continuidad, mientras que el mundo moderno está relacionado con la experiencia de la diferenciación social y la liberación del curso de la vida.

El mundo social en la serie es el "mundo nacional", escenificado a través de temas, problemas y situaciones que son conocidos por los espectadores. Aquí la familia juega un papel especial. A partir de la constelación familiar se desarrolla la narración y la gran parte de los problemas y conflictos. Ciertamente es este aspecto una característica de muchas serials (Mikos, 1994 b). Lo particular en esta serie es, sin embargo, que a través de las familias se representa un tipo de interacción tradicional, donde los padres poseen una función central en la definición de los bosquejos de vida de sus hijos: ellos son una medida moral y un lugar de refugio. No obstante, paralelamente se tematizan otros ámbitos que tienen un carácter globalizante y que en general están asociados con los conflictos al interior del barrio, como es el caso del impacto de empresas multinacionales o de formas de expresión de la "cultura pop global", como la música rock, aeróbicos o movimientos ecologistas, los cuales son vistos como un aporte de los personajes juveniles. Ambos contextos, el local por un lado y el global por el otro, deben considerarse como componentes integrales de las tensiones escenificadas entre tradición y modernidad.

Con relación al futuro social, la serie ofrece un modelo que se desprende de esa representación del mundo social actual y que oscila entre la fragmentación y la cohesión homogenizante: se trata de una imagen trágica del futuro social. El futuro se presenta como una extensión de los problemas del presente: la criminalidad, la ineficiencia del gobierno, o la corrupción institucional empeorarán sino se les ataca a tiempo. La comunidad sería, sin embargo, un lugar de refugio ante esas tendencias sociales, ya que en ese contexto los problemas pueden ser enfrentados por medio de la acción conjunto.

Los modelos de interpretación ofrecidos en la serie para la comprensión de la sociedad están también presentes en el discurso de los jóvenes entrevistados, pero de manera más dramática y expresiva. A la pregunta, cómo caracterizan la sociedad costarricense actual, se pueden citar dos respuestas que resultan paradigmáticas:

\footnotetext{
“En los políticos no le doy a ninguno (.) hay 12 últimos que han ido cayendo (,) antes de esto el país estuvo alto (,) estuvo bien (,) no excelente pero más o menos (,) pero después llegaron los 12 gobiernos y cayeron (.) ahora no es nada no vale nada (,) lo que vale lo debe" 3

"diferente a hace unos años (.) las personas que tienen mucho quieren más y los que tiene poco también quieren mucho (,) se ha vuelto una sociedad ambiciosa y al no poder vienen los problemas los gritos los robos (,) asesinatos (,) suicidios (,) todos estos problemas que se dan últimamente”.
}

\footnotetext{
3 Sistema de transcripción utilizado (Kallmeyer y Schütze, 1976): (,) pausa corta; (...) pausa media; (?) entonación interrogativa; (seguro) entonación marcada.
} 
Desde su punto de vista la sociedad se encuentra en un proceso de deterioro. El presente evidencia el proceso de "descomposición" de una comunidad imaginada, que en un punto mítico de la historia fue armónica, prospera e integrada. Según los jóvenes la sociedad actual es el producto del dominio del orden político económico sobre el mundo de la vida, es decir, este ámbito ha penetrado en una sociedad que según su comprensión era organizada fundamentalmente a través de reglas morales y normas de interacción, muy alejado de lo que sucede en la actualidad, donde la sociedad se estructura más bien según leyes económicas, normas de consumo y luchas de poder a nivel político.

En relación con la organización de la vida cotidiana pueden distinguirse puntos de comparación. Tanto para los jóvenes entrevistados como para algunos de los personajes juveniles de la serie, la vida cotidiana transcurre al interior del triángulo colegio - familia - grupo de pares. La familia y el grupo de pares ocupan una posición de relevancia dentro de esta triada. En la serie se presentan también otras formas de organización que se alejan de la experiencia de los entrevistados, cuya experiencia cotidiana está relacionada más bien con el (los) estilo (s) de vida de la clase media. Sin embargo, los entrevistados reconocen que en la serie se presentan otras experiencias, como es el caso de adolescentes trabajadores, que no van al colegio, los cuales identifican como parte de la realidad actual de Costa Rica. El espacio en el que las acciones se escenifican es conocido: las casas o las calles se asemejan a las propias o, al menos, les resultan familiares.

De manera similar a la serie, se mira el futuro social como la continuación del actual proceso de deterioro. Al respecto señalan dos de los jóvenes:

"Si seguimos así no vamos a tener Costa Rica (,) si seguimos al ritmo que vamos se va a destruir (,) va de mal en peor (,) un desastre".

"Fatal (...) sino se ponen las pilas(,) yo no veo que vaya a crecer (,) las estructuras (,) todo eso se va a perjudicar mucho."

No obstante, se concibe que es posible un cambio de esta tendencia modificando su dirección hacia el restablecimiento de la comunidad perdida. Según la evaluación que realizan los jóvenes, permanecen todavía en la sociedad actual aspectos básicos que posibilitarían dicha reconstrucción, como la democracia, la paz o el sistema educativo. Un cambio significaría una reorganización de la cultura política actual, donde tanto los políticos como los ciudadanos serían participantes activos en el proceso de reestructuración de la sociedad. Al igual que en la serie oscilan las representación del futuro social entre el desamparo y la esperanza.

Hasta ahora se ha señalado como en la serie y en el discurso de los entrevistados se presenta el mismo esquema de interpretación de la sociedad y su futuro. Si bien es cierto no es necesariamente contradictorio con lo hasta ahora planteado, los jóvenes se distancian en sus descripciones de sí-mismos de las imágenes del mundo social, a la que describe a los costarricenses como: "conformistas", "manipulados", "mediocres", "les falta tener más metas y pensar en el futuro". En contraposición con el "ciudadano costarricense" los jóvenes se caracterizan a sí mismos como orientados hacia al futuro, ya que poseen planes concretos y la capacidad para realizarlos. En este sentido, los entrevistados se asemejan más bien a los miembros de la comunidad en la serie, la cual es más cercana a su imagen de una sociedad ideal. En particular, sus representaciones del futuro personal se asemejan a la vida de los personajes que poseen una posición de liderazgo en la serie: una profesión, seguridad económica, una familia y un entorno impregnado de solidaridad. Esto no es una casualidad: la procedencia socio-económica de los entrevistados así como las expectativas culturales en relación con el curso de vida es similar a la de estos personajes. La aspiración a un tal curso de la vida no se le puede equiparar necesariamente con una aceptación acrítica de las "biografías institucionalmente normalizadas" (Normalbiografie) (Kohli, 1998), aportadas por la tradición. Se entiende por "biografías institucionalmente normalizas", la definición institucional de las secuencias que constituyen el curso de la vida. Estas varían dependiendo del género, el estrato socio-económico o de la participación en determinadas subculturas o segmentos culturales (Elder, 1991; Kohli, 1998). Al respecto cabe mencionar las siguientes afirmaciones de los jóvenes: "no me dejo influenciar por la masa" o "[Yo soy, R.P.] una persona que le gustaría estar solo (,) pero no alejado de la gente (,) que le suelten a uno las amarras (,) para irse liberando". Estos planes son vistos más bien como parte de un sí-mismo posible en el que autonomía y autenticidad son afirmados en tanto que cualidades fundamentales de la identidad. Estos aspectos se alejan del curso de la vida tradicional y corresponden a los bosquejos de vida de los personajes jóvenes. 
En este sentido, en sus representaciones del futuro están presentes tanto contenidos ligados a la reproducción de la tradición, como otros de carácter modernizante: al preguntarles a los jóvenes cómo se representan el futuro personal, dos de ellos señalan lo siguiente:

"Tener una familia buena (,) llenarla con lo que necesiten no solo plata (,) no lo veo bien (,) poderles dar una casa que se merezca (,) darle lo que necesitan a los que van a hacer míos".

"Yo me veo como profesional totalmente realizada (,) como profesional (,) con una vida estable (,) con mi carrera que a pesar de tener que trabajar para las clases más altas (,) eeeh (,) sea por sobre todas las cosas humanista (,) llevar una relación con la gente que me rodea $($,$) poder convivir con los demás”....$ "No creo en el matrimonio sino es para legalizar los bienes para mis hijos (,) y el hecho de tener hijos es otro factor que puede influir para no poder llegar hasta donde quiero (...) no sé (...) ya veré"

Al igual que en la serie "El Barrio", es posible distinguir dos modelos de organización de los sí-mismos posibles: por un lado, los objetivos y acciones giran en torno a la familia y la formación de una propia, por el otro, el foco de atención se dirige a la autorrealización y el éxito profesional. Ambos modelos no se presentan necesariamente como contrapuestos, sino más bien yuxtapuestos, de lo que resulta una representación mezclada del futuro personal. Estos resultados pueden verse como un derivado de la globalización en la cultura local, al estar asociada en este caso con la reestructuración del proceso de socialización, la diferenciación de estilos de vida y la reconfiguración de la juventud en tanto que grupo socio-cultural con rasgos propios.

\section{E1 mundo social en "Gute Zeiten - Schlechte Zeiten". Las representaciones del futuro en jóvenes alemanes}

En mundo social en "Gute Zeiten - Scblecbte Zeiten" presenta un mundo de vida desacoplado del sistema político-económico. En la escenificación de la vida cotidiana se concentra la serie en relaciones amorosas o de amistad, dejando de lado el poder político y económico o reduciéndolo a conflictos amorosos o a luchas entre enemigos. Se trata de una sociedad que no tiene un claro nexo con una geografía social y en este sentido se coloca más allá del concepto de nación. Ciertamente la narración y las historias se ubican en una ciudad de una sociedad industrializada -Berlín-: lo que allí sucede, podría suceder, sin embargo, en cualquier parte de Alemania o incluso en otro país, ya que no existe una referencia explícita a una identidad cultural a aún menos a una "identidad nacional".

La sociedad escenificada está determinada por el proceso de individualización y muestra los cambios históricos en el curso de la vida, particularmente al interior del período juvenil, señalado por Fuchs (1983), Kohli (1985) o Büchner (1995). La familia es desplazada por el grupo de pares, quedando en un segundo lugar. Los personajes se orientan al éxito personal y al despliegue de sus estilos de vida, combinando éstos con el compromiso y disposición de ayuda respecto al grupo de amigos. Se trata de un mundo dividido según criterios morales y generacionales. El primer criterio está acompañado por constantes conflictos, los cuales se concretan en los choques constantes entre los personajes "buenos" y los "malos". En el segundo criterio, se pone de relieve la separación entre el mundo de los adultos y el de los jóvenes, ámbitos que transcurren paralelamente sin conflictos, ni roces.

El mundo social representado en la serie se diferencia claramente de la sociedad alemana actual. Es un mundo que desde el punto de vista étnico y socioeconómico es homogéneo. La diversidad cultural que caracteriza a Berlín no se refleja en la composición de los personajes. Se trata de una sociedad de pleno empleo, en la que todos tienen libre acceso al consumo. Por lo demás, el Estado con su función de control no tiene ninguna injerencia en la vida de los personajes: todos los problemas se generan y resuelven al interior de la serie. El sistema educativo es la institución que de forma más clara ejerce una función de control. Otras instituciones del estado aparecen de forma abstracta, esto es, separado de su función histórico-social. Cuando estas instituciones aparecen, se presentan, sin embargo, como sobornables e injustas.

El futuro social en el mundo de la serie es la continuación del estado de cosas presentes. Y es precisamente el presente la dimensión temporal que está en el centro del mundo social escenificado. Sobre el futuro no se reflexiona, éste se muestra más bien incierto e inestable. Éste se limita al devenir de las interacciones entre los personajes, sus problemas y conflictos. Se trata de una secuencia interminable de sucesos, resultando que cada vez que se enfrenta un problema aparece 
uno nuevo. En una sociedad como la que la serie escenifica, donde el bienestar económico y social está asegurado y el poder económico y político tienen un impacto mínimo sobre la vida cotidiana, llega a tener el futuro otro carácter. Éste se desvincula de sus determinantes históricos, para concentrarse en el ámbito de las relaciones íntimas.

El futuro individual tematizado en la serie se despliega de conformidad con escenificación del futuro social. La atención está puesta igualmente en el futuro inmediato: el enfrentamiento de un conflicto concreto o el desarrollo de una relación amorosa. Se parte de un individuo que tiene pleno control sobre su curso de la vida y en cuyo poder yace la potestad de decidir qué tareas ligadas a sus planes de vida - emprender y cuándo. Se trata de un sujeto individualizado, el cual puede definir autónomamente sus bosquejos de vida. En este sentido, la responsabilidad por la aparición de cambios inesperados y el fracaso en la realización de los planes de vida no yacen en el individuo, sino se trata más bien de un golpe del destino o de las acciones que los enemigos realizan contra ellos.

Con relación a la organización de la vida cotidiana de los entrevistados es posible distinguir coincidencias con la cotidianidad de la serie. Al igual que en la serie, el grupo de pares ocupa un lugar central, mientras que la familia se ubica en un segundo plano. Como en la serie, los jóvenes tienen una espacio de acción relativamente abierto, para la definición autónoma de las actividades cotidianas y para la organización del tiempo. En este sentido, las representaciones y experiencias en el discurso de los jóvenes y en la serie son características de la organización moderna del curso de la vida y de sus repercusiones en la redefinición del período juvenil en las sociedades occidentales industrializadas (Fuchs, 1983; Schütze, 1993, Büchner, 1995). Ésto se concreta tanto en el significado particular que ocupa actualmente la familia y el grupo de pares, como en las posibilidades de una configuración relativamente autónoma de la vida cotidiana.

El mundo social escenificado en la serie corresponde solo parcialmente a la representación de los jóvenes de la sociedad alemana actual. Sobre el mundo social de la serie, señala una joven lo siguiente:

“(en ella se presenta, R.P.) el período de clases y cosas así (...) por ejemplo Cora (,) se ve que ella también tiene que ir a clases (,) no es como (,) no es un mundo ideal (beile Welt) donde nadie tiene que hacer tareas (,) ella tiene que escribir trabajos y recibe malas notas o buenas notas (...) que debe de estudiar (,) se ve también que ella tiene que convencer a su papá para poder ir a una fiesta (,) lo que se presenta es sencillamente realidad como en la vida diaria (,) se muestran los desayunos, almuerzos o cenas".

Desde la perspectiva de los entrevistados la sociedad actual se caracteriza por contradicciones de clase, desempleo, criminalidad o, como señala un grupo de ellos, por el impacto negativo de los extranjeros en el desarrollo socio-cultural. Para los entrevistados la serie solo gira en torno a la vida cotidiana, es decir, en torno a historias, personas, estilos de vida o problemas, los cuales tematizan el mundo de vida de un pequeño grupo de personas, pero que deja por fuera el orden macroestructural. La sociedad es evaluada por ellos desde diferentes puntos de vista de carácter político-económico, ecológico o cultural, aspectos que van más allá de la inmediatez de la vida cotidiana. Así se considera:

\footnotetext{
"existen muchas personas sin techo y desempleados (,) y hay muchas personas que tienen demasiado dinero (...) existe una gran diferencia entre pobres y ricos" "[La sociedad actual es, R.P.] Comercial (,) falsa (,) egoísta”
}

$\mathrm{Al}$ contrario de la serie, los jóvenes ponen de relieve la relación entre el mundo de vida y el sistema político-económico, mostrando la determinación progresiva del ámbito macroestructural sobre las interacciones cotidianas, el curso de la vida y la cultura política.

En este contexto, las representaciones del futuro social de los jóvenes sobrepasan también el marco espacio-temporal de la serie. Este futuro es visto como una continuación de los problemas actuales, estando relacionado a un progresivo deterioro de las estructuras sociales. Al igual que en su análisis de la sociedad actual, los entrevistados alemanes interpretan el futuro social tomando en 
consideración diferentes dimensiones, poniéndose de relieve de forma particular los problemas político-económicos. Así un entrevistado considera lo siguiente:

\begin{abstract}
“pienso que todo continuará como está (,) muchos desempleados (...) que nada cambiará en comparación con la situación actual (...) o sea yo no creo que cambie ahora (,) en 20 años o así (...) que haya menos desempleados (...) o que se haga más por la juventud (,) no creo"
\end{abstract}

Muy alejado de un orden económico e institucional estable, que posibilita un desarrollo aproblemático de la biografía normalizada - como sucede en la serie - aparece el futuro social lleno de peligros e incertidumbres. Un cambio sería sin embargo posible, siendo los políticos y el ciudadano mismo los responsables de llevarlo a cabo.

En relación con el futuro personal, es posible distinguir importantes semejanzas entre lo escenificado en la serie y las representaciones de los entrevistados. Aunque las imágenes de la sociedad de los jóvenes se alejan de las de la serie, se encuentran similitudes entre los sí-mismos posibles esbozados por los entrevistados y los personajes jóvenes. Considérese las siguientes aseveraciones de dos de los entrevistados sobre su futuro personal:

\begin{abstract}
"Yo quiero terminar con el colegio (,) con mi Bachillerato (Abitur) (...) después quisiera entrar a estudiar en la universidad (,) todavía no sé qué (,) pero en todo caso ir a la universidad (...) quizá me gustaría también ir a Inglaterra o Estados Unidos para mejorar mi inglés"... "Sobre el tener una familia o algo así (,) no tengo la menor idea”. "A nivel laboral quiero ser médico o dentista (,) o quizás Veterinaria (,) habrá que ver (,) no lo sé (,) yo quiero en todo caso tener una profesión para ser independiente (...) además quiero tener una profesión donde pueda ganar bastante dinero"... "yo no me he puesto ha pensar (,) si en el futuro no quiero definitivamente casarme (,) o si quiero casarme”
\end{abstract}

Si bien la representación del futuro personal no se limita a lo inmediato, se refiere a un espacio de tiempo cuyos límites son la finalización del colegio o el encontrar un puesto de trabajo. El éxito económico y académico son los principales objetivos que definen la organización del futuro personal, tal como sucede también en la serie. La formación de una familia no juega aquí un papel definido o relevante. Se trata más bien de la estructuración de una biografía normalizada que toma como trasfondo una sociedad que tiende hacia una cada vez más intensiva individualización institucional, lo que a su vez está ligado a una progresiva pérdida de los vínculos con la tradición, aspecto que como ya ha quedado claro, se expresa en el papel secundario de la familia dentro de los planes de vida.

Los entrevistados construyen su futuro personal en el marco de un curso de la vida regulado y asegurado institucionalmente. Al igual que en la serie, los jóvenes consideran que ellos tienen control sobre su futuro, además de que tienen la posibilidad de definir autónomamente sus proyectos de identidad. De igual manera que en la serie, solo factores externos de carácter sorpresivo o incontrolado pueden limitar la realización de sus planes. A estas semejanzas le subyace la existencia de un modelo cultural común para la representación del futuro personal: por un lado, este modelo pone de relieve las posibilidades abiertas para la definición y concreción de los planes de vida, las cuales están vinculadas con sí-mismos posibles definidos autónomamente, por otro lado, expresa el papel incierto que juega el futuro social sobre el personal.

\title{
Balance
}

Como muestran los resultados correspondientes a cada país, es posible distinguir dos modelos culturales diferentes, los cuales están presentes tanto en la producción de las series como en su apropiación por parte de los jóvenes estudiados. Es posible, sin embargo, distinguir en ambos países un patrón similar de interacción con el medio.

Mientras la serie costarricense escenifica una sociedad tradicional en proceso de transformación cultural, muestra la serie alemana una sociedad altamente diferenciada. La 
fascinación de los jóvenes entrevistados por ambas series no es casual, pues ambas escenifican los contextos culturales donde ellas están producidas, aportándoles a los jóvenes -de una manera particular- algo que les resulta conocido, es decir, su propia experiencia del mundo social. Precisamente en el contexto de la globalización, jóvenes de ambos países se ven fascinados por lo local, lo conocido, por la propia cultura. En un período histórico que por lo general es considerado como una época de creciente reducción de los vínculos con las formas culturales locales a favor más bien de una cultura transnacional, escogen los jóvenes producciones nacionales. Se trata de una forma de aproximarse a los vínculos entre lo global y lo local, en el caso costarricense desde la tematización del cambio cultural y de los peligros que se le atribuyen, en el caso alemán, desde su autocomprensión de la sociedad en tanto que globalizada e individualizada, mostrando también los problemas que se le adscriben a una tal sociedad.

La apropiación de la serie en ambos países se caracteriza por la clara separación que los jóvenes hacen entre el mundo ficticio de la serie y la propia experiencia del mundo social. Aquí es fundamental la presencia de estrategias cognoscitivas de acercamiento y alejamiento, mediante las cuales los jóvenes comparan su propia experiencia con lo que acontece en la serie. En lugar de contenidos específicos para la construcción de las representaciones del futuro, ofrecen las series, bosquejos de vida, biografías, pautas de acción y escenarios sociales posibles para el despliegue y estructuración del curso de la vida. Éstos son comparados por los jóvenes con los aspectos deseados o temidos de sus propias representaciones del futuro. Aquí es importante señalar que tanto los entrevistados alemanes como costarricenses poseen las competencias mediales que le permiten interpretar y evaluar las respectivas series. Esto se concreta en un conocimiento básico de las características narrativas, estéticas, técnicas o formales que distinguen a los serials.

Sobre la base de este trasfondo pueden distinguirse diferencias relevantes entre los modelos de interpretación del futuro correspondientes a ambos países.

Tanto en las representaciones del futuro personal de los entrevistados costarricenses como al interior del futuro biográfico representado en la serie, se pueden identificar dos modelos de organización de los sí-mismos posibles: por un lado, se presentan biografías las cuales están dirigidas al mantenimiento y reproducción de una sociedad tradicional centrada en la familia, que impone institutional tracks (Greene, 1990; Elder, 1991) o pasajes predeterminados. Por otro lado, se presentan cursos de vida que presionan por liberarse de biografías normalizadas institucionalmente. Aquí se pone relieve, más bien, autonomía y diferenciación cultural, al igual que se representa el intento por liberarse de los ligámenes y controles familiares. Los planes de vida siguen en este caso un propio ritmo, con tareas propias, que pretenden trascender el curso de la vida regulado institucionalmente. Ambos modelos corresponden al desarrollo histórico de la juventud en las sociedades occidentales (Fuchs, 1983; Dudek, 1993; Schütze, 1993). Si se considera el desarrollo de dichas sociedades, tal como es esbozado por Habermas (1997), se podría afirmar que en la serie se escenifica la yuxtaposición de formas culturales tradicionales y tendencias modernizantes, que conducen a la pluralización de los bosquejos de vida y de las identidades. Como ya se ha señalado, ambos modelos están presentes de forma mezclada en el discurso de los entrevistados sobre el futuro.

En el caso de Alemania, el modelo cultural para la representación del futuro presenta características claramente diferentes: tanto en la serie alemana como en el discurso de los entrevistados en dicho país, se constituye el futuro personal en el marco de biografías normalizadas, que se conciben como aseguradas institucionalmente. El modelo cultural para la representación del futuro personal, que aquí se pudo determinar, corresponde a una sociedad moderna, la cual se concibe a sí misma como diferenciada y orientada a la individualización institucional. Desde la perspectiva de los individuos pierde validez el vínculo con un mundo de vida, que era concebido como un todo integrado y homogéneo, para poner de relieve más bien bosquejos de vida individualizados, lo local, la diversidad de formas de agrupación tanto como la capacidad para la concreción autónoma de los planes futuros. El sistema, esto es, el orden político-económico es visto sin embargo como un poder, que aunque alejado de las acciones y vivencias cotidianas, determina y regula el mundo de vida. En este sentido, las representaciones del futuro pueden estar ligadas con dos consecuencias contradictorias en el ámbito de la identidad personal. Por un lado, pueden relacionarse con el proceso de biografización del curso de la vida, lo que significa la construcción reflexiva y autónoma de los sí-mismos posibles tanto como la ampliación institucional del espacio de acción individual (Büchner, 1995; Honneth, 1995; Giddens, 1991). Por otro lado, la construcción de las representaciones del futuro puede estar vinculada con una nueva estandarización de los cursos de vida, la cual pone de relieve un número limitado de estilos de vida 
e institutional tracks, mientras que excluye otras formas de vida e identidades. Paradójicamente los símismos posibles se ven supeditados, en esta segunda vía, a las normas socio-estructurales de regulación del curso de la vida.

Los resultados encontrados llevan a poner en cuestión, el señalamiento, usualmente planteado como un hecho por la psicología de la adolescencia y del ciclo de vida, en el sentido de que un aspecto casi intrínseco de este período es la reflexión sobre el futuro. Al respecto se deben considerar varios aspectos que están presentes tanto en el mundo social escenificado por las series como en el discurso de los jóvenes sobre el futuro: a) La construcción de proyectos de identidad y en general, la reflexión sobre el futuro, está determinada por las tareas de desarrollo a las que cada joven en concreto está siendo frente en un momento dado. De allí que para muchos jóvenes el tema futuro tenga poco importancia, mientras que para otros ocupe un lugar central en el trabajo cotidiano sobre la identidad. De esta manera, temas como vida en pareja, familia o ejercicio de una profesión, tienen un peso diverso. Al respecto se pueden distinguir diferencias ligadas no solo al "desarrollo individual" sino también a la construcción socio-cultural del curso de la vida. El hecho de que el tema familia, resulte menos significativo en los jóvenes alemanes, puede estar relacionado con el hecho de que lo que se entiende por juventud, ocupe por lo general un período de tiempo más extenso que en el caso costarricense, resultando prioritario en el presente otros aspectos. b) Igualmente, el peso que ocupe el tema futuro, depende del significado que el grupo de pares le atribuye a éste. El papel que puede tener la familia a este respecto varía dependiendo de, por un lado, si los jóvenes orientan su vida cotidiana en torno a ella, o por otro lado, como ya se ha visto, de diferencias culturales ligadas a un curso de vida tradicional o individualizado. c) La intensidad con la que los jóvenes se ocupan de los sí-mismos posibles depende también de grado en el que las biografías normalizadas están estructuradas y garantizadas institucionalmente. Así por ejemplo, en Alemania aspectos como formación profesional o técnica, elección de oficio, búsqueda de empleo, están altamente regulados y parcialmente garantizados por el Estado, esto no ocurre así en Costa Rica, en donde el joven tiene que hacerse cargo de decisiones, posibilidades y restricciones ligadas a los planes de vida, sobre las cuales el Estado tiene poca injerencia, resultando la familia y el joven mismo los que tienen que ocuparse de las posibilidades de realización de dichos planes.

Los resultados aquí presentados abren una serie de interrogantes o áreas temáticas que pueden orientar futuras investigaciones sobre el tema: a) El uso de otros métodos para el estudio tanto de las representaciones de futuro como de la recepción televisiva, que permitan indagar en la tematización al interior de las conversaciones cotidianas de ambos temas, tanto en el marco del grupo familiar como del grupo de pares. b) El indagar en otros ámbitos de los sí-mismos posibles que se ubiquen más allá de las biografías normalizadas institucionalmente, y que se refieren a aspectos de carácter específicamente biográfico-expresivos, ligados a estilos de vida o "subculturales". c) El análisis de las particularidades que presenta el proceso de recepción serial y la construcción de proyectos de identidad en diferentes grupos socioculturales, para lo cual se hace necesario diseñar estudios que tomen en cuenta las diferencias por género, grupo étnico, nivel socioeconómico, proveniencia rural o urbana o edad.

\section{Referencias}

Allen, R. (1995). Introduction. En A. Robert (Ed.), To be continued... soaps operas around the world (pp. 1-25). Londres: Routledge.

Anderson, B. (1998). Die Erfindung der Nation. Zur Karriere eines folgenreichen Konzepts. Berlin: Ullstein.

Appadurai, A. (1998). Modernity at large. cultural dimensions of globalization. Mineapolis: University of Minnesota Press.

Barker, C. (1997). Television and the reflexive project of the self: Soaps, teenage talk and hybrid identities. British Journal of Sociology, 48, 611-628.

Barker, C. (1999). Television, globalization and cultural identities. Buckingham: Open University Press.

Bauer, M. (2000). Classical content analysis: A review. En W. Bauer y G. Gaskell, (Eds.). Qualitative research with text, image and sound (pp 131-151). Londres: Sage.

Beck, U. (1986). Risikogesellschaft. Auf dem Weg in eine andere Moderne. Francfort: Suhrkamp.

Bermúdez, M. (1994). La influencia de los valores televisivos en los adolescentes de los sectores urbanos populares. San José: Escuela de Ciencias de la Comunicación Colectiva, Universidad de Costa Rica. 
Bilden, H. (1997). Das Individuum - ein dynamisches System vielfältiger Teil-Selbste. Zur Pluralität in Individuum und Gesellschaft. En H. Keupp (Ed.), Identitätsarbeit Heute. Klassische und aktuelle Perspektiven der Identitätsforschung (pp 227-249). Francfort: Suhrkamp

Büchner, P. (1995). The impact of social and cultural modernization on the everyday lives of childrens. Theoretical and methodological framework and first results of an intercultural Project. En M. Du Bois-Reymond; R, Diekstra; K, Hurrelmann y E, Peters (Eds.), Children and young in Germany and the Netherlands. Transitions and coping strategies of adolescents (pp. 105-125). Berlin: Walter de Gruyter.

Buckingham, D. (1993). Children talking television. The making of television literacy. Londres: Falmer Press.

Cantor, M. y Pingree, S. (1983). The soap operas. California: Sage.

Charlton, M. (1997). Rezeptionsforschung als Aufgabe einer interdisziplinären Medienwissenschaft. En M, Charlton y S, Schneider. Rezeptionsforschung. Opladen: Westdeutscher Verlag.

Charlton, M. y Neumann, K. (1990). Medienrezeption und Identitätsbildung. Kulturpsychologische und kultursoziologische Befunde zum Gebrauch von Massenmedien im Vorschulalter. Tubinga: Gunter Narr.

Charlton, M. y Neumann-Braun, K. (1992). Medienkindheit - Medienjugend: eine Einfübrung in die aktuelle kommunikationswissenschaftliche Forschung. Munich: Quintessenz Verlag.

Cross, S. y Markus, H. (1991). Possible selves across the life-span. Human Development, 34, 230-255.

De Volder, M. (1979). Time orientation: A review. Psychologica Belgica, XIX, 61-79

Dobles, I. y Fournier, M. (1996). Algunas características psicosociales de la juventud en la región metropolitana del valle central de Costa Rica. San José: Organización Panamericana de la Salud/Instituto de Investigaciones Psicológicas (UCR).

Dudek, P. (1993). Geschichte der Jugend. En H.H., Krüger (Ed.), Handbuch der Jugendforschung (pp 305-331). Opladen: Leske y Budrich.

Eco, U. (1988). Über Spiegel und andere Phänomene. Carl Hanser Verlag.

Elder, G. (1991). Lives and social change. En W. Heinz. (Ed.), Theoretical advances in life course research (pp. 58-86). Weinheim: Deutscher Studien Verlag.

Ferchhoff, W. (1999). Jugend an der Wende vom 20. zum 21. Jabrbundert. Lebensformen und Lebensstile. Opladen: Leske y Budrich.

Frey-Vor, G. (1990). Charakteristika von Soap operas und Telenovelas im internationalen Vergleich. Media Perspektiven, 8, 90, 488-496.

Frotz, F. (1996). Der symbolisch-interaktionistische Beitrag zur Untersuchung von Mediennutzung und Rezeption. En U. Hasenbrink y U. Frotz. Die Zuschauer als Fernsebregisseure?. Zum Verständnis individueller Nutzungs- und Rezeptionsmuster (pp. 52-75). Hamburgo: Nomos.

Fuchs, W. (1983). Jugendliche Statuspassage oder Individualisierte Jugendbiographie? Soziale Welt, 34, 341-371.

Glaser B. y Strauss, A. (1998). Grounded theory. Strategien qualitativer Forschung. Gotinga: Huber.

Gergen, K. (1994). Realities and relationships. Cambridge: Harvard University Press.

Giddens, A. (1991). Modernity and self-identity. Self and society in the late modern age. Gran Bretaña: Stanford University Press.

Greene, A. L. (1986). Future-time perspective in adolescence: The present of things future revisited. Journal of Youth and Adolescence, 15, 99-113.

Greene, A. L. (1990). Great expectations: Constructions of the life course during adolescence. Journal of Youth and Adolescence, 19, 289-306.

Grob, A.; Flammer, A y Rhyn, H. (1995). Entwicklungsaufgaben als soziale Normsetzung: Reaktionen Erwachsener auf Lösungsmodi von Entwicklungsaufgaben Jugendlicher. Zeitschrift für Sożalisationsforschung und Erreiebungssoziologie, 15, 44-62.

Habermas, J. (1997). Theorie des Kommunikativen Handelns (Tomo 2). Auflage. Francfort: Suhrkamp.

Habermas, T. (1986). Geliebte Objekte. Symbole und Instrumente der Identitätsbildung. Berlin: Walter de Gruyter.

Hall, S. (1996). Encoding/decoding. En S. Hall; D. Hobson; A. Lowe y. P. Willis. Culture, media, language (pp 128138). Londres: Routledge.

Hall, S. (1997). The local and the global: Globalization and ethnicity. En A. King (Ed.), Culture, globalization and the world system (pp 19-40). Minneapolis: University of Minnesota Press. 
Heitmeyer, W. y Hurrelmann, K. (1993). Sozialisations- und handlungstheoretische Ansätze in der Jugendforschung. En H. Krüger. Handbuch der Jugendforschung (pp 109-133). Opladen: Leske y Budrich.

Heitmeyer, W. y Olk, T. (1995). The role of individualization theory in adolescent socialization. En G. Neubauer y K. Hurrelmann (Eds.), Individualisation in childhood and adolescence (pp 15-35). Berlin: Walter de Gruyter.

Hepp, A. (1998). Fernsehaneignung und Alltagsgespräche. Fernsehnutzung aus der Perspektive der Cultural Studies. Opladen: Westdeutscher Verlag.

Hermans, H. y Kempen, H. (1993). The dialogical self. Meaning as movement. Londres: Academic Press.

Hodge, R. y Tripp, D. (1986). Cbildren and television. A semiotic approach. Oxford: Polity Press.

Honneth, A. (1995). Desintegration. Bruchstücke einer soziologischen Zeitdiagnose. Francfort: Fischer.

Kallmeyer, W. y Schütze, F. (1976). Konversationsanalyse. Studium Linguistik, 1, 1-28.

King, A. (1997). Introduction: Spaces of culture, Spaces of Knowledge: En A. King. (Ed.), Culture, Globalization and the World System (pp 1-18). Minneapolis: University of Minnesota Press.

Kohli, M. (1985). Die Institutionalisierung des Lebenslaufs. Historische Befunde und theoretische Argumente. Kölner Zeitschrift für Soziologie und Sozialpsychologie, 37, 2-29.

Kohli, M. (1998). Lebenslauftheoretische Ansätzen in der Sozialisationsforschung. En K. Hurrelmann y D. Ulich (Eds.), Handbuch der Sozialisationsforschung (pp 303-317). Weinheim: Beltz.

Livingstone, S. (1996). Die Rezeption von Unterhaltungsangeboten. Zum Stand der Publikumforschung. En U. Hasenbrink y U. Frotz (Eds.), Die Zuschauer als Fernsehregisseure?. Zum Verständnis individueller Nutzungs- und Rezeptionsmuster (pp 163-177). Hamburgo: Nomos.

Livingstone, S. (1998). Making sense of television. The psychology of audience interpretation. Londres: Routledge.

Lewin, K. (1951). Field theory in social science. Nueva York: Harper.

Lobo, I. y Robert, J. (1996). La televisión y el niño costarricense. San José. Editorial Universidad de Costa Rica.

Lüders, C. (1991). Deutungsmusteranalyse. Annäherungen an ein risikoreiches Konzept. En D, Garz y K, Kraimer (Eds.), Qualitativ-empirische Sozialforschung. Konzepte, Methoden, Analyse (pp 377-408). Opladen: Westdeutscher Verlag.

Martín-Barbero, J. (1995). Memory and form in the Latin American soap-opera. En R. Allen (Ed.), To be continued... soap operas around the world (pp 276-284). Londres: Routledge.

Markus, H. y Nurius, P. (1986). Possible selves. American Psychologist, 41, 954-969.

Markus, H y Wurf, E. (1987). The dynamic self-concept: A social psychological perspective. Annual Review of Psychology, 38, 299-337.

Mayring, P. (1985). Qualitative Inhaltsanalyse. En G. Jüttemann (Eds.), Qualitative Forschung in der Psychologie (pp 187-211). Weinheim: Beltz.

Mayring, P. (1997). Qualitative Inhaltsanalyse. Grundlagen und Techniken. Weinheim: Beltz

Mead, G. (1967). Mind, self and society from the standpoint of a social behaviorist. Chicago: The University of Chicago Press.

Mikos, L. (1994a). Es wird dein Leben!. Familienserien im Fernsehen und im Alltag der Zuschauer. Münster: MAKS Publikationen.

Mikos, L. (1994b). Fernsehen in Erleben der Zuschauer. München: Quintessenz.

Münchmeier, R. (1997). Die Lebenslage junger Menschen. En Jugendwerk der Deutschen Shell. Jugend '97. Zukunftsperspektiven, gesellschaftliches Engagement und politische Orientierungen (pp 277-301). Opladen: Leske: Budrich.

Neumann-Braun, K. (1993). Rundfunkunterhaltung. Zur Inszenierung publikumsnaher Kommunikationsereignisse. Tubinga: Gunter Narr Verlag.

Nurmi, J.-E. (1989). Adolescents orientation to the future. Development of interests and plans, and related attributions and affects, in the life-span context. Helsinski: The Finnish Society of Sciences and Letters.

Nurmi, J.-E.; Poole, M. y Seginer, R. (1995). Tracks and transitions. A comparison of adolescent future-oriented goals, explorations, and commitments in Australia, Israel and Finland. International Journal of Psychology, 30, 355-375.

Nurmi, J.-E.; Seginer, R. y Poole, M. (1995). Searching for the future in different environments: A comparison of australian, finnish and israeli adolescents' future orientations, exploration and commitments. En P. Noack; M. Hofer y J. 
Youniss. Psychological responses to social change. Human development in changing environments (pp 219-237). Berlin: Walter de Gruyter.

Oevermann, U. (1991). Genetischer Strukturalismus und das sozialwissenschaftliche Problem der Entstehung des Neuen. En S. Müller-Doohm (Ed.), Jenseits der Utopie (pp 267-368). Francfort: Suhrkamp.

Oevermann, U. (1993). Zur Analyse der Struktur von Deutungsmuster. Manuscrito no publicado. Universidad de Francfort.

Pasquier, D. (1997). La televisión como experiencia. En E. Verón y L. Escudero (Eds.), Telenovela. ficción popular y mutaciones culturales (pp 235-250). Barcelona: Gedisa.

Pieterse, J. N. (1995). Globalization as hybridization. En M. Featherstone; S. Lash y R. Robertson. Global modernities (pp 45-68). Londres: Sage.

Poole, M. y Cooney, G. (1987). Orientation to the future: A comparison of adolescents in Australia and Singapore. Journal of Youth and Adolescence, 16, 129-151.

Robertson, R. (1995). Globalization: time-space and homogenity-heterogenity. En M. Featherstone; S. Lash y R. Robertson. Global modernities (pp 25-44). Londres: Sage.

Schütze, Y. (1993). Jugend und Familie. En H.H. Krüger (Ed.), Handbuch der Jugendforschung (pp 335-350). Opladen: Leske y Budrich.

Silverstone, R. (1994). Televisión y vida cotidiana. Argentina: Amorrortu.

Steinke, I. (1999) Kriterien Qualitativer Forschung. Weinheim: Juventa.

Strauss, A. y Corbin, J. (1998). Basics of qualitative research. Techniques and procedures for developing grounded theory. California: Sage

Straus, F. y Höfer, R. (1997). Entwicklungslinien alltäglicher Identitätsarbeit. En H. Keupp y R. Höfer (Eds.), Identitätsarbeit Heute. Klassische und aktuelle Perspektiven der Identitätsforschung (pp 270-307). Francfort: Suhrkamp.

Torres-Rivas, E. (1993). La cuestión juvenil en Costa Rica. San José: FLACSO.

Trommsdorff, G., Lamm, H. y Schmidt, R. (1979). A longitudinal study of adolescents future orientation (time perspective). Journal of Youth and Adolescence, 8, 131-147.

Turner, J. C. (1987). Rediscovering the social group. A self categorization theory. Nueva York: Basil Blackwell.

Valles, M. (1997). Técnicas cualitativas de investigación social. Madrid: Síntesis

Vygotsky, L. (1964). Denken und Sprechen. Berlin: Akademie Verlag.

Widdicombe, S. (1988). Dimensions of adolescent identity. European Journal of Social Psychology, 18, 471-483

Witzel, A. (1985). Das Problemzentrierte Interview. En Jüttemann, G. (Eds.), Qualitative Forschung in der Psychologie (pp. 227-255). Weinheim: Beltz. 